\title{
DISSERTAÇÕES DE MESTRADO E TESES DE DOUTORADO/2013
}

Universidade Federal do Rio de Janeiro

Centro de Filosofia e Ciências Humanas

Instituto de Psicologia

Programa de Pós-graduação em Teoria Psicanalítica

\section{DISSERTAÇÕES}

\section{Título: Identidade e diferença na relação com a alteridade}

Autora: Augusta Rodrigues de Oliveira

Zana

Orientadora: Simone Perelson

Data de defesa: janeiro/2013

O objetivo deste trabalho é discutir a relação com a alteridade a partir de duas ordens de reconhecimento. No capítulo 1, discutimos a experiência de satisfação, como proposta por Freud (1895/1996) no "Projeto para uma psicologia científica", e apresentamos sua análise sobre o que acontece quando o objeto da percepção é outro ser humano, enunciando o complexo do próximo (Nebenmensch). Em seguida, discutimos a formulação do estranho em Freud (1919/1996) e sua releitura por Lacan (1959-1960/1997) como o não representado, por meio do conceito de das Ding. No capítulo 2, partimos do narcisismo no texto freudiano "Sobre o narcisismo: uma introdução” (1914/1996) e do estádio do espelho em Lacan (1949/1998a) para chegar ao conceito de identificação, que é discutido fundamentalmente a partir das formulações de Lacan (1956-57/1995) no Seminário 4. Finalizamos o capítulo com as operações de alienação e separação apresentadas por Lacan (1964/2008 a) no Seminário 11 e retomadas no seminário
O ato psicanalítico (1967-68). No capítulo 3 , trabalhamos com duas ordens de reconhecimento, sendo a primeira, a partir das leituras de Honneth (2003) e Szpacenkopf (2011), focalizada na relação entre indivíduos e circunscrita ao campo da representação. Apresentamos a crítica da categoria da identidade por duas vias: pela desconstrução da categoria de identidade empreendida por Butler (1998; 2003; 2010) e pelo descentramento do sujeito proposto pela psicanálise e trabalhado por Birman (2003). Em seguida, discutimos, a partir de Cunha (2009) e Safatle (2012), outra ordem de reconhecimento, que leva em conta o estranho e não apenas a relação imaginária entre indivíduos, permitindo tratar do reconhecimento da não identidade. Chegamos finalmente a uma tentativa de compatibilizar essas duas ordens de reconhecimento, retomando considerações dos autores já referidos e apresentando as proposições de Hardt e Negri (2005).

Título: 0 estatuto teórico $d a$ metapsicologia freudiana Autor: Caio Padovan Soares de Souza Orientadora: Ana Beatriz Freire Data de defesa: fevereiro/2013

Com base no estudo de pesquisas conduzidas por Sigmund Freud, e por outros 
psicanalistas e pesquisadores contemporâneos àquele autor, esta dissertação tem como objetivo contribuir para a definição do estatuto teórico da metapsicologia. Por 'estatuto teórico' entende-se aqui o conjunto de princípios que regem determinado tipo de construção teórica. Nossa hipótese inicial é a de que a metapsicologia está condicionada, nos termos do seu estatuto e enquanto teoria psicanalítica, aos imperativos de uma forma particular de experiência que teria lugar na clínica psicanalítica. Com vistas a avaliar esta hipótese, dedicamo-nos ao estudo de alguns textos de caráter clínico e metodológico escritos por psicanalistas e publicados entre as últimas décadas do século XIX e o início do século XX. Esta delimitação se justifica por duas razões. A primeira delas tem relação com o necessário recorte temático exigido por um trabalho deste porte; a segunda está baseada na aposta de que um estudo a respeito das condições de possibilidade da metapsicologia seria mais bem sucedido se dirigido ao próprio contexto de surgimento desta disciplina. Os resultados obtidos durante a pesquisa confirmaram nossas expectativas em torno do valor da experiência para a elaboração metapsicológica, sendo possível concluir que há nesta experiência uma espécie de critério empírico capaz de avaliar a pertinência de um dado constructo teórico. Ao que tudo indica, tal critério vem coincidir com aquele usado pelo clínico em uma análise, a saber, o da manifestação das resistências, o que parece atestar uma coincidência — sustentada por Freud desde os seus primeiros trabalhos - entre pesquisa e tratamento no contexto da prática psicanalítica. Outra importante conclusão a que chegamos é a de que a objetividade deste critério, capaz de revelar aquilo que viemos chamar de uma materialidade psíquica, não é a mesma observada entre as ciên- cias experimentais, situação que parece evidenciar uma suposta impossibilidade de tratar a experiência psicanalítica em termos quantitativos (matemáticos) ou em categorias descritivas universalizáveis.

\section{Título: Ver e olhar: contribuições psicanaliticas sobre a cegueira} Autora: Cintia Rita de Oliveira Magalhães Orientadora: Simone Perelson/Regina Herzog Data de defesa: fevereiro/2013

Na teoria psicanalítica, a visão parece possuir certa primazia em relação aos demais sentidos. Já no início de sua obra, Freud destaca a importância das impressões visuais na estruturação do psiquismo. Ao teorizar sobre a primeira vivência de satisfação, ele demonstra o caráter visual desta experiência que abre espaço para a emergência do desejo. O olho deixa de ser, exclusivamente, fonte da visão e passa a ser fonte da libido que o erogeniza, pois para Freud ele é um órgão que está a serviço de dois senhores: pulsões do Eu e pulsões sexuais. No primeiro grupo, ele serviria para a apreensão da realidade e no segundo seria envolvido pela função sexual. Logo, pode-se dizer que o corpo constituído a partir do narcisismo é derivado de sensações corporais. Contudo, sua relação com o mundo externo também é de grande importância, pois grande parte de sua própria forma é adquirida a partir dessa interação com o mundo externo - visões vistas, sons ouvidos, corpos tocados, prazeres explorados. Em função disso, podemos nos perguntar de que maneira uma pessoa cega vivenciaria esses processos. Logo, o presente trabalho tem por objetivo fazer uma reflexão acerca 
da cegueira à luz da psicanálise, partindo, principalmente, da distinção entre o ver e o olhar.

\section{Título: Os lugares do analista no ensino de Lacan}

Autor: Erly Alexandrino da Silva Neto Orientadora: Tânia Coelho dos Santos Data de defesa: março/2013

Este trabalho conduzirá um estudo sobre os lugares do analista ao longo do ensino psicanalítico de Jacques Lacan. Partindo da formulação de seu vigésimo terceiro seminário, a de que o psicanalista é um sinthoma, não pretende deixar dúvidas a respeito do lugar que Lacan concede ao analista: ele é real, não é ficção, não é convenção nem mais um profissional psi a disputar o mercado, mas o trauma do forçamento a uma nova escrita do gozo, e é a partir deste lugar que ele é eficaz. O pressuposto que este estudo sustenta, portanto, é de que o correto estatuto do lugar do analista é indispensável para a eficácia de suas intervenções. Entretanto, as formulações finais de Lacan — especialmente na forma como aparecem nas produções teóricas dos analistas contemporâneos — não são apreensíveis sem a condução de uma espécie de exegese de suas elaborações anteriores, que é a tarefa a que se propõe esta dissertação. Deste modo, após estabelecer um assoalho conceitual e teórico a partir dos escritos freudianos sobre a técnica da psicanálise, retomará o início que o próprio Lacan estabelece para o seu ensino, 1951, e percorrerá seus cursos e escritos iniciais para estabelecer os fundamentos de sua teoria, e a tônica de seu retorno à Freud. Após isso, sistematizará o núcleo de seu ensino, o período que Miller chamou de lacanismo 'clássico', para estabelecer com rigor e precisão a estrutura simbólica do sujeito e da experiência analítica, sempre dando relevo aos lugares do analista e suas relações com o real. Por fim, mostrará como o seminário sobre a ética da psicanálise revisou o estatuto do real e introduziu a Coisa freudiana como precursora do objeto agalma, no seminário sobre a transferência, e do objeto a como causa do desejo, no seminário da angústia. A título de indicações, percorrerá as formulações do seminário sobre os quatro conceitos fundamentais da psicanálise que é onde o próprio Lacan situa o início de seu segundo ensino - no intuito de apontar as linhas de desenvolvimento que culminarão no axioma da não relação sexual, nas fórmulas da sexuação e do analista como traumatismo.

\section{Título: Da castração como rochedo freudiano d̀ vertente feminina da sexuação lacaniana \\ Autora: Fernanda Oliveira Queiroz de Paula Orientadora: Tânia Coelho dos Santos Data de defesa: fevereiro/2013}

A presente pesquisa busca delimitar as especificidades da sexuação feminina para a psicanálise. A incidência do complexo de castração e do complexo de Édipo, operadores simbólicos que ordenam a diferença sexual sob a égide da lógica fálica, não se efetua da mesma maneira nos homens e nas mulheres. Há uma dissimetria na constituição subjetiva feminina e masculina devido ao fato desvelado por Freud de que, apesar da existência de dois sexos anatômicos no inconsciente só há o princípio do falo. Com isso, a primazia fálica e a falta de uma representação no inconsciente que designe o que é uma mulher são 
as consequências psíquicas da distinção anatômica entre os sexos. Entretanto, o que Freud desenvolveu acerca da sexualidade feminina e da feminilidade foi com base na lógica masculina da sexuação, definida por Lacan como lógica do todo. Isso o colocou diante de impasses acerca do processo da sexuação feminina, e a questão do feminino fica como um enigma: "O que quer uma mulher?", "O que é ser uma mulher?". Ao final de sua obra, Freud concebe que o complexo de castração é um rochedo no processo de sexuação de ambos os sexos e um "osso" no processo analítico, e equivale os impasses da sexuação àqueles encontrados ao final de uma análise. Partindo do retorno de Lacan à obra freudiana, apoiamo-nos na sua afirmação de que Freud não avançou para além desse rochedo por não conseguir sair do lugar de identificação ao pai ideal do Édipo. Do mesmo modo, constatamos no percurso de Lacan, que é apenas quando este consegue dar um passo além do pai edipiano como Outro consistente, que lhe é possível avançar na formalização da vertente feminina da sexuação. Desse modo, a presente pesquisa busca apresentar a interseção entre a transposição do pai ideal ao pai implicado à sua causa de desejo, assim como a transposição da dimensão do conceito lacaniano de Outro enquanto consistente - A - , ao seu estatuto inconsistente $-\mathrm{S}(\mathrm{A})$ - , como os passos que permitiram Lacan ultrapassar a castração como um rochedo freudiano, rumo à formalização inédita, da vertente feminina da sexuação, com base em uma lógica para além do falo e da lógica do todo: a lógica do não-todo.
Título: Corpo e alteridade: processo de subjetivação

Autora: Jôse Lane de Sales

Orientadora: Regina Herzog

Data de defesa: fevereiro/2013

A presente dissertação se propõe a abordar a questão da constituição da subjetividade em uma perspectiva psicanalítica. Seu objetivo é investigar como se dá o complexo processo de subjetivação no qual a questão corporal e a função da alteridade possuem papel relevante. O primeiro capítulo será dedicado ao exame do registro do corpo autoerótico, que tem lugar no pensamento de Freud com a introdução da ideia de uma sexualidade infantil e do conceito de pulsão sexual. O segundo se propõe a pensar o registro do corpo narcísico unificado, que surge em 1914 e se radicaliza em 1923 com a concepção de um Eu-corporal. O último abordará o que se designa como o corpo irrepresentável, o qual adquire proeminência a partir do conceito de pulsão de morte em 1920. Para articular a questão da alteridade com cada um desses registros, visando trabalhar aspectos mais precoces do desenvolvimento subjetivo, recorreremos a outros autores, privilegiadamente Donald Winnicott, Piera Aulagnier e Sándor Ferenczi.

\section{Título: A transmissão psíquica e o negativo constituinte}

Autora: Ludmilla Tassano Pitrowsky Orientadora: Simone Perelson

Data de defesa: março/2013

Neste trabalho, procuraremos discutir a seguinte questão: haveria na transmissão psíquica inconsciente conteúdos da ordem do negativo que seriam constitutivos no 
processo de estruturação psíquica? Para colocarmos tal questão, faremos um estudo teórico a respeito dos temas: a transmissão psíquica, o negativo e a constituição psíquica. No primeiro capítulo, introduziremos a teoria de René Kaës acerca da transmissão psíquica, principalmente em seus diálogos com a teoria freudiana. Dentro do vasto estudo de René Kaës, pesquisaremos seu desenvolvimento acerca da teoria da transmissão psíquica inconsciente, desde os primeiros momentos em que o tema pode ser encontrado em seus estudos com Didier Anzieu, até sua mais recente publicação acerca dos vínculos implicados no processo de transmissão geracional, as alianças inconscientes. No segundo capítulo, discutiremos o conceito de negativo através de André Green, precursor da questão do trabalho do negativo através também das obras de Freud. Após vislumbrarmos alguma compreensão de sua teoria, entraremos na "transmissão-repetição”, conceito trazido por René Kaës ao tratar a transmissão psíquica em duas vertentes: positiva e negativa. Neste momento, traremos autores que nos ajudem a pensar tal proposta, como Haydée Faimberg, Tatiana Inglez-Mazzarella, Jô Gondar, Luiz Alfredo Garcia-Roza, entre outros. No terceiro capítulo traremos possíveis campos de investigação do negativo constituinte do psiquismo que nos seria transmitido inconscientemente. Desta forma, traremos os conceitos de Introjeção e incorporação de S. Ferenczi, desenvolvidos por N. Abraham e M. Torok para em seguida estudarmos a teoria da sedução generalizada de J. Laplanche. Na terceira parte deste terceiro capítulo, abordaremos os conceitos de sombra falada e contrato narcísico de Piera Aulagnier e, por fim, da possibilidade de pensarmos a violência fundamental de Jean Bergeret. No momento final desta dissertação, discutiremos os problemas, dificuldades e possíveis conclusões do nosso percurso em busca da colocação e discussão de nossa questão.

\section{Título: Confluências entre as neuroses atuais e as patologias da atualidade} Autor: Paulo Giovani Goulart Ritter Orientadora: Marta Rezende Cardoso Data de defesa: março/2013

O objetivo deste trabalho é propor linhas de convergência entre as neuroses atuais, designação estabelecida por Freud nos anos 1890, e as patologias da atualidade, cujas configurações psíquicas, por diferirem das organizações subjetivas de cunho neurótico e exigirem ferramentas técnicas distintas das habituais, têm desafiado a teoria e a clínica psicanalíticas. Realizamos uma releitura das neuroses atuais à luz de avanços teóricos posteriores da elaboração freudiana. Nessa releitura, as ideias de insuficiência psíquica e excesso de excitação, base de sua concepção das neuroses atuais, são articuladas ao conceito de narcisismo e à noção de excesso pulsional, o que permite pensá-las como estreitamente referidas à dimensão de precariedade narcísica e ao campo do traumático.

Mostramos como as neuroses atuais levantam a mesma questão que a figura da neurose traumática coloca em cena em 1920 - o excesso pulsional —, questão fundamentada nos conceitos de pulsão de morte e de compulsão à repetição. Esta análise nos permite explorar as patologias contemporâneas, de base traumática, em que o excesso pulsional atinge níveis inéditos, aspecto correlativo aos limites dos processos de ligação e representação, marca do impacto traumático da pulsão. Como resultado desse processo, há o in- 
cremento de respostas defensivas elementares, com apelo ao registro do corpo e ao do ato. Assim, defendemos a ideia de que as neuroses atuais apresentam elementos importantes que iluminam o entendimento das patologias contemporâneas.

\section{Título: Da questão da transferência ao surgimento de um novo dispositivo clínico: o que o autismo nos ensina}
Autor: Rafael Ferreira Lima Dias
Orientadora: Ana Beatriz Freire
Data de defesa: abril/2013

Esta dissertação tem por objetivo levantar os impasses da oferta da psicanálise aos ditos sujeitos autistas, a partir da problematização da transferência na clínica com a psicose. Para tanto, levantamos a hipótese do autismo como tipo clínico do campo da psicose. A transferência na psicose é uma questão que impulsiona os analistas, e a clínica com esses pacientes é fonte de inúmeras pesquisas. A partir dos impasses freudianos com a transferência na clínica da psicose, veremos como Lacan em seu retorno à Freud provoca uma reviravolta introduzindo a linguagem, o significante e o gozo no campo psicanalítico. Desta forma ele concebe condições preliminares para todo o tratamento possível da psicose. Veremos também como o mesmo Lacan deixou indicações preciosas quanto à clínica com os sujeitos autistas. Veremos como os impasses da oferta da psicanálise para sujeitos autistas propiciou a construção de dispositivos que permitem a inclusão desta entidade clínica.
Título: A marca de Tânatos: o traço melancólico no texto literário

Autora: Rita Isadora Pessoa Soares de Lima

Orientadora: Anna Carolina Lo Bianco

Data de defesa: março/2013

A possibilidade de interlocução entre a psicanálise e a literatura ao mesmo tempo em que impulsiona esta pesquisa, constitui, também, um desafio. Desde a antiguidade, a melancolia apresenta uma extensa trajetória através dos registros médicos e da história da arte. Se esta trajetória é, portanto, povoada de múltiplas metamorfoses, fez-se necessário mapear uma série delas para então cingir o nosso objeto de pesquisa - o traço melancólico no texto literário. A estreita relação entre a melancolia e a pulsão de morte — sendo a primeira descrita por Freud em 1923 como a pura cultura da pulsão de morte - nos conduziu rumo à identificação de uma relação entre o destino pulsional da sublimação e o predomínio da pulsão de morte na melancolia. Freud fez algumas considerações acerca dos riscos em jogo no trabalho sublimatório, e Lacan, de alguma forma, retoma tal posição em seu seminário sobre a ética, em 1959, quando afirma que a sublimação é uma tarefa para além do princípio de prazer, uma vez que, a rigor, ao dessexualizar a pulsão, passa a não estar mais a serviço de Eros. Partindo daí, a busca por um eixo que permanecesse constante ao longo das transformações e derivas sofridas pela melancolia no decurso dos séculos se coloca como uma etapa importante no processo de cernir o traço melancólico. Alguns autores e poetas possuem vozes e obras nas quais podemos mais facilmente identificar a presença do traço melancólico. A obra final da poeta norte-americana Sylvia Plath foi escolhida por nós para análise e estudo de caso. 
Título: Caps-AD Alameda: um trabalho orientado pela psicanálise no campo da Saúde Mental

Autora: Tatiana Lins Serra Cattapan Orientadora: Fernanda Costa-Moura Data de defesa: junho/2013

Propõe-se, nesta dissertação, uma articulação entre a Psicanálise e o campo da Saúde Mental. Pretende-se discernir o campo da Saúde Mental, orientado por princípios como a ressocialização e a cidadania, da psicanálise, que incide sobre a relação do sujeito com seu desejo. Ao definir alguns pressupostos do campo da Saúde Mental, construídos no movimento da reforma psiquiátrica, pretende-se mostrar de que forma o Caps AD foi inserido no campo da Saúde Mental. A contribuição da psicanálise para o campo da Saúde Mental é discutida a partir de uma investigação sobre os conceitos de demanda e desejo, apoiada nos trabalhos de Freud e Lacan. Ressalta-se a importância do aspecto imperativo da pulsão, visto na compulsão à repetição em sujeitos toxicômanos. A partir destes fundamentos retoma-se uma experiência de trabalho orientado pela psicanálise no Caps AD Alameda, dispositivo da Rede de Saúde Mental do município de Niterói/Rio de Janeiro, na qual se evidenciaram, em situações da prática cotidiana do processo de recepção neste serviço, as dificuldades da entrada em tratamento de pacientes toxicômanos. Através de um fragmento de caso clínico discute-se a dificuldade de adesão do paciente ao tratamento oferecido no Caps-AD Alameda, e a fragilidade na ligação com o terapeuta, que coloca em risco todos os ideais da reforma psiquiátrica, enfatizando a grande dificuldade de incidência das políticas publicas de tratamento e prevenção na vida desses sujeitos.
Título: "Como seria belo ser uma mulher": transexualismo masculino e empuxo-d̀-mulher

Autor: Wellington Carlos Moreira Júnior Orientadora: Angélica Bastos

Data de defesa: março/2013

Esta pesquisa interroga a relação entre o transexualismo e o efeito de empuxo-à-mulher nas psicoses. Adota-se como referencial teórico-clínico a psicanálise, em especial, os ensinos de S. Freud e J. Lacan. O objetivo consiste em verificar a presença do empuxo-à-mulher no transexualismo, partindo da advertência de J. Lacan sobre a face psicótica dos transexuais que será explicada pela presença da foraclusão do significante paterno nesses sujeitos. O procedimento buscou investigar a tendência à feminização, tão evidente na orla da psicose. Do estudo paradigmático de Freud (1911/1996) sobre o presidente Schreber, destacou-se a prevalência da fixação narcísica e da poderosa defesa erguida pelo sujeito diante da irrupção da libido homossexual. Lacan (1957-58/1998), diferindo de Freud, propôs o conceito gozo transexualista circunscrevendo, sob esse prisma, a prática de transformação em mulher vivenciada por Schreber. Em outro momento do seu ensino, Lacan nomeou a manifestação do gozo na psicose como efeito de empuxo-à-mulher (Lacan, 1973/2003), o que suscitou, nesta pesquisa, a interrogação sobre se este último corresponderia a uma atualização do conceito gozo transexualista. Tal indagação orientou o desenvolvimento da dissertação, cuja pertinência reside no fato de que a convicção do sujeito de ser mulher, a despeito do que se verifica na morfologia do seu corpo, é uma manifestação clínica própria da psicose. Nota-se nesses sujeitos uma grande dificuldade em acessar o 
dispositivo simbólico, a partir do qual se delimitaria, no discurso, a resposta sobre a diferença sexual: o que é um homem, o que é uma mulher. Ao mesmo tempo, observa-se que eles recorrem ao atributo da imagem para estabelecer tal diferença. A pesquisa é de cunho teórico-clínico, baseando-se em casos da literatura especializada e em publicações com depoimentos e entrevistas de transexuais. A dissertação se divide em quatro partes: uma revisão histórica do conceito de transexualismo; uma discussão entre a proposta stolleriana, a freudiana e a lacaniana sobre a diferença sexual; um estudo sobre o gozo transexualista e o efeito de empuxo-à-mulher e, por fim, uma discussão entre essas duas formulações lacanianas do gozo na psicose e o transexualismo. Nesta última seção, faz-se uso de dois casos da literatura, Amanda e Tininha Nova York, nos quais a manifestação do transexualismo demonstrava a clara ação do efeito de empuxo-à-mulher. Discute-se também a necessária indicação cirúrgico-hormonal, feita pela ciência médica, para o transexualismo. Conclui-se que, a presença da foraclusão no discurso do sujeito, revelada na sua convicção em ser mulher, indica a ação do efeito de empuxo-à-mulher. Este compõe uma definição ampla para o gozo nas psicoses, e se aplica às múltiplas faces da representação deste gozo, indo além do gozo transexualista, que supõe apenas uma das representações consequentes do efeito de empuxo-à-mulher. 